\title{
An Experimental Investigation of Cutting Temperature and Tool Wear in 2 Dimensional Ultrasonic Vibrations Assisted Micro-Milling
}

\author{
Mohd Rasidi Ibrahim ${ }^{1}$, Zulafif Rahim ${ }^{1}$, Erween Rahim ${ }^{1}$, Latif Tobi ${ }^{1}$, Kai Cheng ${ }^{2}$, Hui Ding ${ }^{3}$ \\ ${ }^{1}$ Faculty of Mechanical \& Manufacturing Engineering, Universiti Tun Hussein Onn Malaysia, Parit Raja, Johor, Malaysia \\ ${ }^{2}$ Advance Manufacturing Engineering Enterprise, School of Engineering and Design, Brunel University, West London UB8 3PH, \\ ${ }^{3}$ School of Mechatronics Engineering, Harbin Institute of Technology, Harbin 150001, China
}

\begin{abstract}
Two dimensional Ultrasonic vibration assisted milling (2D UVAM) well knows process that involved in high tech system to generate ultra range of frequency applied to the milling process. More industries nowadays become aware taking this opportunity to improve their productivity without decreasing their product accuracies. This paper investigate a comparative machining between UVAM and conventional machining (CM) in tool wear and cutting temperature in milling process. Micro amplitude and sine wave frequency will be generate into the workpiece jig by piezo-actuator. Thus, creating a micro gap that allow heat remove effectively with the chip produces. A more complex tool trajectory mechanics of 2D UVAM has been found during this research. The approaching the tool tip into the workpiece surfaces is affected by the amplitude displacement along the frequency applied. It is found that the tool wear was reduce and surface roughness improvement by applying the 2D UVAM compared to the CM when choosing the optimum amplitude and appropriate frequency.
\end{abstract}

\section{Introduction}

The using of advance and high machine technology for manufacturing production has become increasingly year by year. The high demand become seriously affected by the rapid innovation and new technology especially in telecommunication, military, aerospace, electronic gadget etc. Moreover, the development of new high specification and high strength material is a new challenge to the researcher and industries to fabricate for making a mould, tools, jig, die and so on.

Common conventional milling is a traditional method that needs to be improving along the technology development. Thus, 2D UVAM is the one machining system that attracted researcher worldwide for improving time to time. Lian and Guo found the surface roughness on the machining surfaces of Al6061 has smaller roughness that machining by ordinary micro-milling [1]. They conclude the UVAM has addition tool trajectory making the surface better than CM. It has been proved by their mathematical modeling by using Matlab software to simulate the trajectory of the cutter tooth in Figure 1.

Coating technology has one of the solutions for solving the wear problem in machining. The coatings are about $3 \mu \mathrm{m}-5 \mu \mathrm{m}$ layer applied to the cutting tool especially in end mill on the tool tip. It is no doubt the coated tool proven hardened the endmill and approximately up to 80 to $100 \mathrm{GPA}$ and thermal stability $1200^{\circ} \mathrm{C}$ [2]. However, the cost to coat the endmill to its application is below the expectation to some of the small scale industries. The experiment has been carried out to investigate machinability improvement between $\mathrm{CM}$ and 2D UVAM focused on the tool wear and cutting temperature looking deeply on the tool UVAM locus trajectory.

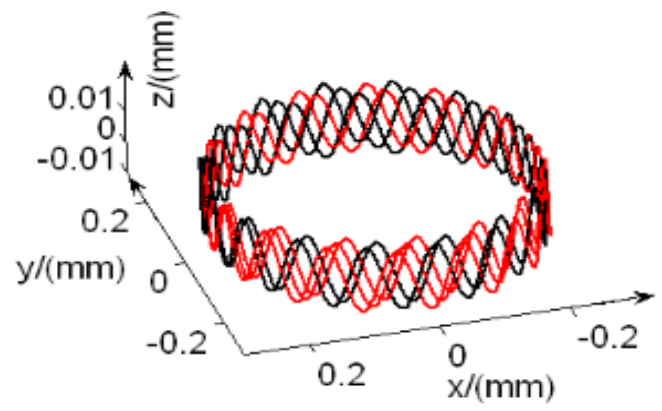

Figure 1. Trajectory tool in UVAM.

\section{Cutting temperature and tool life}

Rubbing and friction during ploughing and shearing during milling process create exponential energy. As a consequence the energy will convert to heat and spread between the tool and the workpiece. The temperature on the rake face angle has a strong effect on tool life [3]. When the tool tip temperature increases, the changes of 
graphitization molecules will that soften the tool rapidly occur. The increasing of temperature will affect the tool life because of:

- $\quad$ Raising of cutting force/speed

- Constant stress between tool and workpiece

- Inappropriate cooling medium

- Tool becoming blunt

Intermittent cutting in VAM creates a gap between the tool and the workpiece. This can be expressed:

$$
\begin{aligned}
& y=a \sin \omega t \\
& x=b \cos \omega t
\end{aligned}
$$

Where $y, x$ and $\omega$ are the displacement, amplitude acting in $X, Y$ axis and angular velocity of tool tip respectively. In conventional machining, the tool is always kept in contact with the workpiece so the heat will increase as long as it is still in contact. The tool cutter will soften more than half of their hardness when reaching high temperatures.

In 2D UVAM, this will not happen as the temperature remains constant so as to maintain the tool's hardness. Figure 2 shows the mechanism in of 2D UVAM towards workpiece. It also shows how the intermittent mechanism, by amplitude and frequency pulse impacts on tool separation from the chip, promotes aerodynamic lubrication increases. Consequently, shows the tool path mechanism of conventional machining. In addition, the clearance angle and rake angle are free from cutting force and release the stress of pressure from the rubbing and ploughing process.

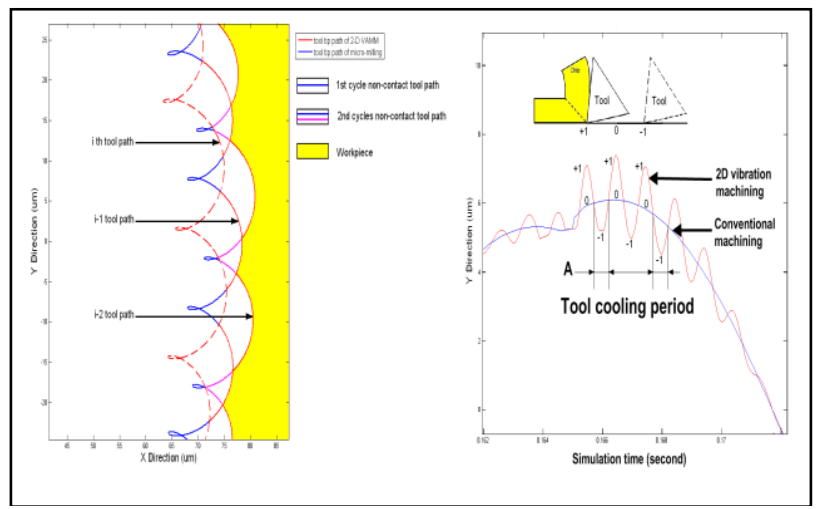

Figure 2. Mechanism of 2D UVAM during the cooling period.

The displacement of tool vibration in the cutting operation at a frequency in the period of $\mathrm{A}$. The digging/ploughing between point +1 and -1 is to remove material causes chips to form. The retraction tool and workpiece between points +1 to -1 promoted dynamic force for the chip to leave the cutting area efficiently. Thus, this beneficial strongly agrees with Shaw theory that $90 \%$ of the heat generated goes into chips, $5 \%$ into the workpiece and 5\% into the tool [4].

Figure 3 shows a simulation created from Matlab platform showing the cooling gap that has been created during the VAM cutting process. With the parameters a is
$3 \mu \mathrm{m}, \mathrm{b}$ is $1 \mu \mathrm{m}$, frequency $\mathrm{X}$ and $\mathrm{Y}$ are $1,000 \mathrm{~Hz}$, feedrate is $2 \mu \mathrm{m}$ per tooth and spindle speed is $2,000 \mathrm{rpm}$. The clearance or gap during alternating motion allows heat transfer to work efficiently toward air or coolant, cooling down the tool and surface of the workpiece, which prevents the cutting temperature on the tool and workpiece rising especially, in very hard and very soft materials. It also reduces the time available for tools to change their molecular structure or for other types of wear.

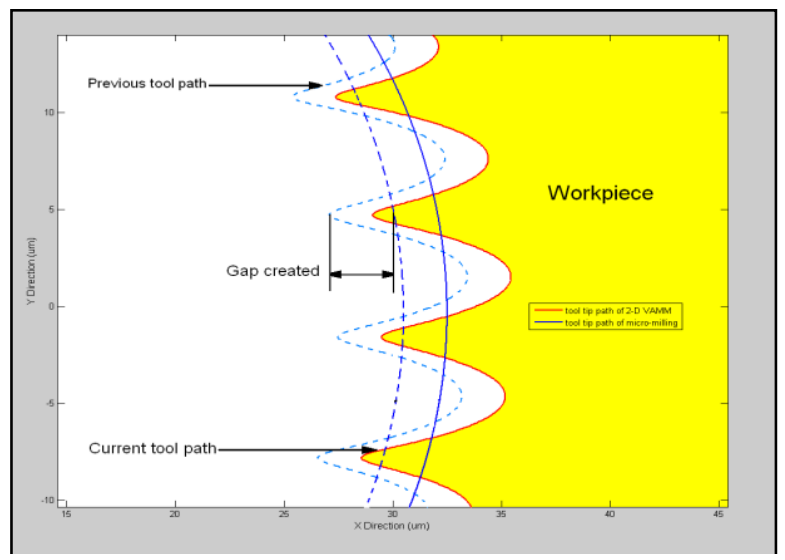

Figure 3. Gap in 2D UVAM influence the tool temperature and tool life.

It is found, during the intermittent cutting, that VAM creates a small energy instantaneous mechanics to lower down tool force affect the decreasing the local stress on the tool. It has been reported that the tendency of cutting force reduces about $40 \%$ to $50 \%$ by alternating cycles by frequency and amplitude.

\section{Surface roughness}

The surface produced by conventional milling depends on the result of geometric and kinematic reproduction of the tool point shape factor [4]. Through the experimental studies, the concavity and axial relief angle in the end mill has a big effect on the surface produced, especially on the peak to valley measurement. Figure 4 shows the simulation of mechanics cutting by conventional machining and 2D UVAM from side view.

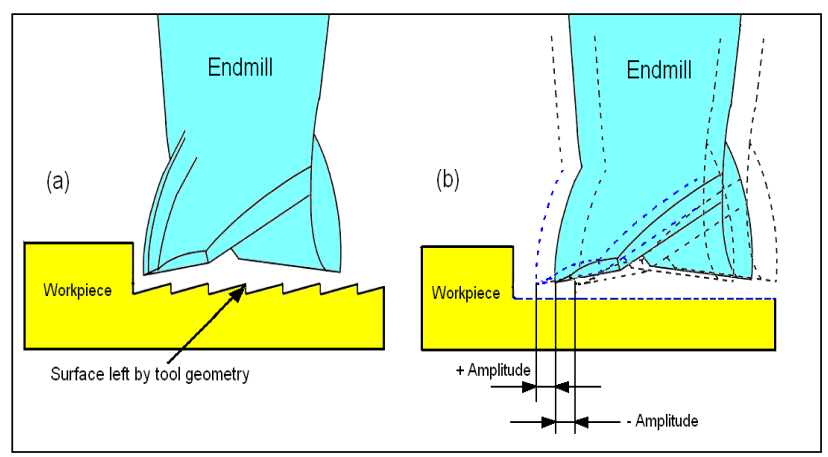

Figure 4. (a) Effect in 2D UVAM in surfaces, (b) Effect of CM in surfaces.

The circular motion nature of 2D UVAM allows the tool cutting point to traverse the cut area from the 
preceding cycle and remove the material peaks and valleys left over from the last time. During the cutting circular motion of 2D UVAM, the smaller force will deduce the average force and promote to surface accuracy and surface finish by compensating the relative vibration between cutter and workpiece. In addition from that point the reduced tool cutting force also insist chatter on the surface produced.

So, by investigating the Figure 4, the peak to valley of the surface has been reduced by the cutter via an overlapped process. The higher frequency of cutting, the more chances there is of the tool cutter in one particular area reducing the peak and valley to obtain a good surface result. Rasidi and Ding found the 2D UVAM was helping to cut the crest of the surfaces into smaller pieces while opposing the frequency and amplitude thus, eliminated by the alternating cycles phenomena [5]. From this, we observe that the good surface is made by cutting the crests and peak on the surface with the vibratory tool.

\section{Experimental case study}

Figure 5 shows the comparison of 2 tools that have been cut without 2D UVAM (a) and with aid of 2D UVAM (b). The distance of slot cutting is extended to $90 \mathrm{~mm}$ to $90 \mathrm{~mm}$ to observe the tool wear. Figure a clearly shown the wear on the rake angle surface due to abrasive wear. Abrasive wear cause by two common reasons, first the cutting speed increase affect the tool surface sliding in a short time period. Second, rapid increasing a temperature in the cutting area. The hardness of the tool material wills drops directly proportional with temperature. These phenomena called a thermal softening behaviour. Figure (b) shows the abrasive wear has take part as same position as Figure (a), but there is approximately $60 \%$ reduction of the worn area. It is because the 2D UVAM create an "instantaneous gap" helping the chip flush away efficiently thus reduced the temperature. In result from that, 2D UVAM chip produced much smaller and shorter chip instead large and continuous chip in CM. [6]. So the temperature in 2D UVAM is reduced and keep constant thus prevent the tool changes the hardness properties. It will keep the tool last longer during the cutting process.

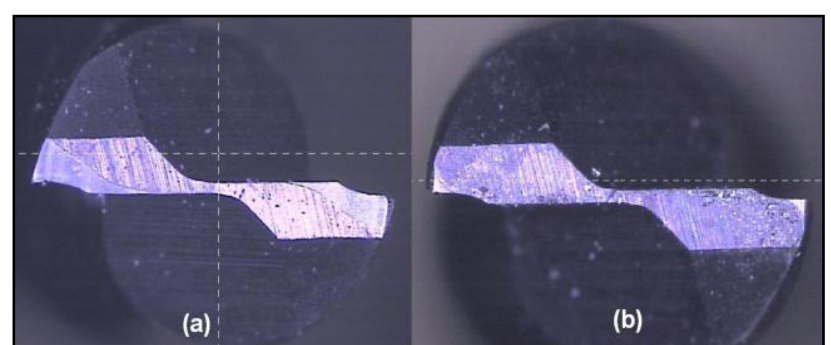

Figure 5. Tool wear (a) without 2D VAM (b) with 2D VAM.

\section{Conclusion}

From this paper we can conclude the 2DUVAM have distinct advantages compared with conventional machining methods summaries on Table 1 below.

Table 1. Summary camparison between CM and 2DUVAM.

\begin{tabular}{|c|c|c|c|}
\hline & Conventional Milling & Vibration assisted milling & Comments \\
\hline $\begin{array}{l}\text { Cutting } \\
\text { temperature }\end{array}$ & $\begin{array}{l}\text { - No gap to dissipate heat } \\
\text { energy. } \\
\text { - Tool always making contact } \\
\text { with workpiece. }\end{array}$ & $\begin{array}{l}\text { - Alternating cycles (gap) promotes heat } \\
\text { dissipate between cutting tool and } \\
\text { workpiece, therefore } 40 \% \text { to } 50 \% \text { heat } \\
\text { reduced. } \\
\text { - Less time contact between tool and } \\
\text { workpiece providing chances of tool and } \\
\text { workpiece to release heat energy. } \\
\text { - Lubricating flowing resulting form } \\
\text { periodic tool-work separation. } \\
\text { - the work-tool contact area varies at } \\
\text { several points on the elliptical path. }\end{array}$ & $\begin{array}{l}\text { - } 100 \% \text { cutting time tool } \\
\text { point keep in contact on } \\
\text { conv. machining with the } \\
\text { workpiece, but in 2D } \\
\text { VAM, the clearance } \\
\text { distance has been created } \\
\text { when the tool point } \\
\text { retracted from the } \\
\text { workpiece. }\end{array}$ \\
\hline Tool life & $\begin{array}{l}\text { - Temperature rising is } \\
\text { accumulating to soften the } \\
\text { tool. } \\
\text { - Tool always in contact and } \\
\text { always in stress and strain } \\
\text { condition. }\end{array}$ & $\begin{array}{l}\text { - Constant temperatures encourage tool } \\
\text { cutter have an extra hardness and } \\
\text { strength ability. (Thermal softening } \\
\text { theory). } \\
\text { - } 40 \% \text { to } 50 \% \text { time contact reduced } \\
\text { between rake angle and clearance angle } \\
\text { and workpiece chances of tool to release } \\
\text { stress force. } \\
\text { - Intermittent contact between tool and } \\
\text { work material in VAM reduces the time } \\
\text { available for graphitization and other } \\
\text { wear reactions. }\end{array}$ & $\begin{array}{l}\text { - Tool life in conv. } \\
\text { machining is reduced } \\
\text { cause by thermal } \\
\text { softening theory cause by } \\
\text { high temperature, but in } \\
2 \mathrm{D} \text { UVAM, the } \\
\text { temperature will constant } \\
\text { and reduced } 30 \%-40 \% \text {. } \\
\text { - Tool failure ratio from } \\
\text { stress and strain is low. }\end{array}$ \\
\hline
\end{tabular}

\section{Acknowledgement}

The authors would like to thank Registrar Office, ORICC UTHM for facilitate in this research, Precision Machining
Research Centre (Premach) UTHM and lastly the Cedrat Technology SA for providing the piezo-actuator system. 
1. H. Lian., Z. Guo,Z. Huang, Y. Tang, J. Song : Experimental Research of AL6061 on Ultrasonic Vibration Assisted Micro-Milling, The Seventeenth CIRP Conference on Electro Physical Chemical Machining (ISEM) volume 6, (2013)

2. Information

on

http:// http://www.endmill.com/pages/coatings.html

3. Negeishi, N. Elliptical vibration-assisted machining with single crystal diamond tools" MS thesis, North Carolina State University, 2003.

4. Shaw, C. "Energy conversion in cutting and grinding", Annals of the CIRP, 1996, 101-104.

5. I. Rasidi, N. H Rafai, E. A. Rahim, S.A. Kamaruddin, H. Ding and K. Cheng: An investigation of Cutting Mechanics in 2 Dimensional Ultrasonic Vibration Assisted Milling Toward Chip Thickness and Chip Formation, $3^{\text {rd }}$ International Conference of Mechanical Engineering Research, IOP Conference Series: Material Science volume 100 (2015).

6. I, Rasidi, N.H. Rafaai, E. A. Rahim, S. A. Kamruddin, H. Ding and K. Cheng: An investigation of Cutting Mechanics in 2 Dimensional Ultrasonic
Vibration Assisted Milling toward Chip Thickness and Chip Formation, 3rd International Conference of Mechanical Engineering Research (ICMER 2015), IOP Conf. Series, Material Science and Engineering 100, 2015.

7. Brehl, D., and Dow, A.: Review of vibration-assisted machining. Precision Engineering, 32, 2008, 153-172.

8. Yusuf, A. "Manufacturing Automation: Metal Cutting Mechanics, Machine Tool Vibrations and CNC Design. Cambridge University Press, 2000.

9. I, Rasidi, N.H Rafai, E.A. Rahim, S. A. Kamaruddin, H. Ding and K. Cheng : An investigation of cutting mechanics in 2 dimensional ultrasonic vibration assisted milling toward chip thickness and chip formation

10. Ahmed, N., Mitrofanov, A., Babitsky, V., and Silberschmidt, V. "Analysis of forces in ultrasonic assisted turning". Journal of Sound and Vibration, 2007, 308, 845-854. 